\title{
Functional and structural changes in aorta of mice divergently selected for basal metabolic rate
}

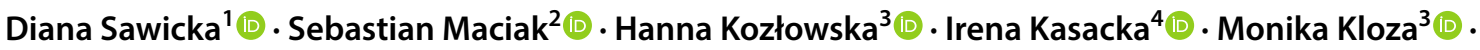

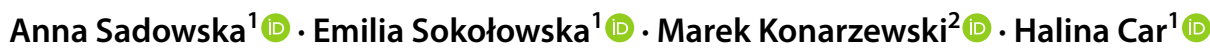

Received: 30 August 2019 / Revised: 29 November 2019 / Accepted: 8 December 2019 / Published online: 23 December 2019

(c) The Author(s) 2019

\begin{abstract}
Cardiovascular diseases (CVD) are one of the most common causes of mortality likely genetically linked to the variation in basal metabolic rate (BMR). A robust test of the significance of such association may be provided by artificial selection experiments on animals selected for diversification of BMR. Here we asked whether genetically determined differences in BMR correlate with anatomical shift in endothelium structure and if so, the relaxation and contraction responses of the aorta in mice from two lines of Swiss-Webster laboratory mice (Mus musculus) divergently selected for high or low BMR (HBMR and LBMR lines, respectively). Functional and structural study of aorta showed that a selection for divergent BMR resulted in the between-line difference in diastolic aortic capacity. The relaxation was stronger in aorta of the HBMR mice, which may stem from greater flexibility of aorta mediated by higher activity of $\mathrm{Ca}^{2+}$-activated $\mathrm{K}^{+}$channels. Structural examination also indicated that HBMR mice had significantly thicker aorta's middle layer compared to LBMR animals. Such changes may promote arterial stiffness predisposing to cardiovascular diseases. BMR-related differences in the structure and relaxation ability of aortas in studied animals may be reminiscent of potential risk factors in the development of CVD in humans.
\end{abstract}

Keywords Basal metabolic rate $\cdot$ Aortic function $\cdot$ Mouse

Communicated by G. Heldmaier.

Diana Sawicka and Sebastian Maciak had equal participation.

Diana Sawicka

diana.sawicka@umb.edu.pl

1 Department of Experimental Pharmacology, Medical University of Bialystok, ul. Szpitalna 37, 15-295 Białystok, Poland

2 Department of Evolutionary and Physiological Ecology, Faculty of Biology, University of Bialystok, ul. Ciołkowskiego 1J, 15-245 Białystok, Poland

3 Department of Experimental Physiology and Pathophysiology, Medical University of Bialystok, ul. Mickiewicza 2A, 15-089 Białystok, Poland

4 Department of Histology and Cytophysiology, Medical University of Bialystok, ul. Mickiewicza 2C, 15-222 Białystok, Poland

\section{Introduction}

There is a growing evidence that the rate of energy expenditure may be an informative marker of health status in humans (Costantino et al. 2016; Félétou 2009; Martens and Gelband 1996; Russell and Proctor 2006). Among different metrics of energy turnover, basal (BMR) or resting (RMR) metabolic rates attract increasing attention because of mounting data of their association with multimorbidity (Fabbri et al. 2015; Maciak and Michalak 2015; Mancini et al. 2011). BMR is quantified as the minimum rate of energy expenditure necessary to sustain bodily functions in resting, post-absorptive endotherms at thermoneutral conditions, whereas RMR refers to the level of minimum MR measured under more relaxed conditions, outside the thermometric zone, with no need to meet fasting state (Schmidt-Nielsen 1997). BMR (or RMR) accounts for 60-70\% of daily energy expenditure (DEE) of humans and, therefore, serves as a useful proxy of DEE, which is relatively easy to assess via indirect calorimetry (Pelley 2012).

Several studies indicate that above-average energy expenditures may be a significant risk factor for modern 
world diseases (Dang 2012; Maciak and Michalak 2015; Mancini et al. 2011) and general multimorbidity (Fabbri et al. 2015). Similarly, the pro-inflammatory status of an organism and overall immunological activation are correlated with an increased BMR, which remains attributable to overall metabolic dysregulations and considered the main indicator of mortality (Ferrucci et al. 2005; Heilbronn et al. 2006). Conversely, below-average BMR is associated with metabolic thrift and obesity (Hamilton et al. 2007; Sadowska et al. 2017). Moreover, variation in the rate of metabolism translates not only to physiological, but also to anatomical differentiation. According to previous studies, BMR is strongly correlated with the mass of internal organs such as heart, liver, kidney and small intestine (Brzęk et al. 2007; Konarzewski and Książek 2013), and-for example-with a size of cells building those organs (Maciak et al. 2014). Therefore, increasing evidence from both, studies on humans and animal models suggest that physiological and anatomical differences in the rate of metabolism can translate into susceptibility to the development of serious illnesses (Ghebre et al. 2016; Kathiresan and Srivastava 2012; Maciak and Michalak 2015; Nunney 2018; Sadowska et al. 2017).

Although a general relation between energy expenditures (particularly at the level of RMR/BMR) and multimorbidity seems well established, the exact mechanisms and direction of this association are still not well understood. This applies in particular to cardiovascular diseases (CVD), which remain the most common cause of death worldwide (Kathiresan and Srivastava 2012; Tune et al. 2017; Wells et al. 2016). Few longitudinal data, linking CVD with socalled metabolic syndrome, indicate that low energy expenditure and sedentary lifestyle are risk factors for weight gain, arthrosclerosis, hypertension, and finally development of cardiovascular disorders (Hamilton et al. 2007). However, there is no hard evidence for such increased risk in the general population or unselected cohorts (Mancini et al. 2011; Prentice 2008). What is more, other studies suggest that an increase in the production of reactive oxygen associated with elevated aerobic metabolism constitutes a substantial risk of CVD development (Costantino etal. 2016; Wells et al. 2016).

At the structural level, abnormalities of the endothelial layer of vessels may be a critical factor for the initiation and development of vascular disorders (Costantino et al. 2016). The endothelial cells play an important function in basal vascular tone regulation by the nitric oxide (NO) and/or prostacyclins responsible for relaxation and sealing the blood vessels (Deanfield et al. 2007; Katusic et al. 2012). The mediators produced by the vascular endothelium inhibit the aggregation of blood platelets, lower blood pressure and prevents cardiovascular disease (Ghebre et al. 2016; Kirkby et al. 2014; Yun et al. 2016). In the pathogenesis of atherosclerosis (the most common syndrome of CVD), it comes into endothelium damage and inner membrane of the vessel with lipids and macrophages accumulation. The resulting atheromatous plaque may narrow or even completely close the vessel light or it may break with the release of the embolic material (Skoczynska and Martynowicz 2005). Similarly, changes in vascular structure and function of large arteries are easily seen in aging individuals (Costantino et al. 2016). Most often, agerelated impairments of vascular arrangement are the result of phenotypic alterations of different cell types building large vessels and being a direct consequence of deregulation of genes involved in metabolic rate performance (Costantino et al. 2016; Sawabe 2010). Hence, to understand genetic and physiological mechanisms promoting CVD, it is of high relevance to investigate its putative associations with the rate of energy expenditures, particularly BMR and/or RMR.

Since over 30 years, constructing relevant genetically modified animal models of pathophysiological mechanisms has become a method of choice. In many cases, such an approach has provided critical insights into understanding of studied processes (Russell and Proctor 2006; Zadelaar et al. 2007). Since, however, both, metabolic rate (Konarzewski and Książek 2013) and CVD (Kathiresan and Srivastava 2012) are by-products of multiple genes underlying distant physiological traits, comprehensive animal models for studies on the associations between those two are not available. An important initiative would be the creation of a consensus on the most effective animal models for the study of the various aspects of CVD. This must be based on the recognition of the complex multifactorial traits directly related to CVD rather than simplified molecular genetics (Russell and Proctor 2006). To fill this gap, here we used laboratory mice from longterm divergent selection for high and low basal metabolic rate, characterized by a $50 \%$ differentiation in BMR that is unmatched by any other animal model (Sadowska et al 2017). Apart from the difference in BMR, the lines differ distinctly with respect to the relative sizes of metabolically active internal organs, including heart (Konarzewski and Książek 2013) as well as metabolic risk indicators, such as per cent of body fat mass, blood lipid profile and fasting blood glucose levels (Sadowska et al. 2017).

Here, we examined the potential relationship between the variation in BMR and anatomical, as well as physiological properties of the thoracic aorta in the above animal model. We asked whether genetically determined changes in BMR are coupled with anatomical shift in endothelium structure and so the relaxation and contraction responses of the aorta. We also investigated vascular contractile and vasodilatation function of the aorta. Thus, we aimed at developing a novel framework for studying metabolism as a risk factor of susceptibility to the development of cardiovascular diseases. 


\section{Materials and methods}

\section{Animals}

We used 22-week-old laboratory male Swiss-Webster mice (Mus musculus) from two lines divergently selected for high (thereafter HBMR line, $n=5$ ) and low (thereafter LBMR line, $n=5$ ) basal metabolic rate. The selection experiment is carried out at the Department of Evolutionary and Physiological Ecology, Faculty of Biology, University of Bialystok. The sample size of five and the use of males only were dictated by an extremely time-consuming nature of measurements described therein. With larger sample size and females included, the time required to complete the study would incur unavoidable age differences of experimental animals, which would confound the interpretation of our findings.

Animals were housed before the test in temperature $23 \pm 0.1{ }^{\circ} \mathrm{C}$ and $12 \mathrm{~d}: 12 \mathrm{n}$ photoperiod. Mice had unlimited access to water and food. Following completion of BMR measurements (see below) animals have been anesthetized by intraperitoneal administration of a mixture of ketamine and xylazine (50 mg/kg and $5 \mathrm{mg} / \mathrm{kg}$, respectively), then terminal exsanguinations have been performed. All procedures were carried out in accordance with the European Directive (2010/63/EU) and with the consent of Local Ethical Committee on Animal Testing (University of Olsztyn, Permit Number 9/2016).

\section{Metabolic measurements}

Metabolic measurements have been performed between 8 am and $8 \mathrm{pm}$. BMR has been measured by positive-pressure opencircuit respirometry system with dried and warmed atmospheric air. The air stream was divided into four streams that were powered separate mass flow controller with the rate of $400 \mathrm{~mL} \mathrm{~min}^{-1}$. The mouse had been individually placed in $350 \mathrm{~cm}^{3}$ chambers immersed in a water bath at $32^{\circ} \mathrm{C}$. The air stream coming from the chambers was directed to the Sable Systems TR-1 oxygen analyzer (Henderson, NV, USA). The air was picked up at speed $75 \mathrm{~mL} \mathrm{~min}^{-1}$ and before being moved through the oxygen sensor it was cleared of moisture and $\mathrm{CO}_{2}$. The metabolic test lasted $3 \mathrm{~h}$ and oxygen concentration in each chamber was investigated every second for $2 \mathrm{~h}$. BMR has been set as the lowest level of oxygen consumption that has not changed for at least $4 \mathrm{~min}$ by more than $0.01 \%$. Performance analysis was based on Sable System DATACAN V software.

\section{Vessel preparation}

The thoracic aorta was removed carefully to prevent endothelium injury and placed in cold Krebs-Henseleit solution of the following composition (in $\mathrm{mM}$ ): $\mathrm{NaCl} 118$; $\mathrm{KCl}$ 4.8; $\mathrm{CaCl}_{2} 2.5 ; \mathrm{MgSO}_{4} 1.2 ; \mathrm{NaHCO}_{3} 24 ; \mathrm{KH}_{2} \mathrm{PO}_{4}$ 1.2; glucose 11; EDTA 0.03 and $\mathrm{pH} 7.4$.

The aorta rings (approximately 3-mm-long vessel segments) were carefully cleaned of adherent tissue and were mounted as ring preparations in an isometric small vessels Mulvany-Halpern-type wire myograph (Model 620M, Danish Myo Technology, Aarhus, Denmark, Mulvany and Halpern 1977). The vessels were threaded on two stainless steel wires, $40 \mu \mathrm{m}$ in diameter, attached to a force transducer and a micrometer, respectively. In this way, the myograph permitted direct measurement of vessel wall tension while the internal diameter was controlled. Tensions were measured and recorded on the LabChart 7.3.7 Pro (ADInstruments, Hastings, UK). All aorta rings were set at tensions that were equivalent to their mean in vivo (100 $\mathrm{mmHg}$ ) using the Laplace equation with a normalized lumen diameter as described by Mulvany and Halpern (1977). All vessels were kept at $37{ }^{\circ} \mathrm{C}$ in gas with $95 \%$ $\mathrm{O}_{2}$ and $5 \% \mathrm{CO}_{2}$ Krebs-Henseleit solution and were allowed to equilibrate for $30 \mathrm{~min}$ (resting tension $5 \mathrm{mN}$ ). After the equilibration period and prior to the administration of antagonists, inhibitors or vehicles, all of the rings were exposed to two stimuli of high $\mathrm{KCl}(60 \mathrm{mM})$ to establish tissue viability. The second $\mathrm{KCl}$ was used to determine maximum contractility of the tissue. After washing out the $\mathrm{KCl}$, the integrity of the vessel endothelium was checked for sub-maximal pre-constriction with (-)-phenylephrine (Phe, $3 \mu \mathrm{M}$ ) followed by the induction of at least $80 \%$ relaxation in response to acetylcholine (Ach, $10 \mu \mathrm{M})$. Before certain experiments, the endothelium was removed by gently rubbing the intima. A successful endothelial denudation was confirmed by the absence of acetylcholineinduced vasorelaxation (Baranowska-Kuczko et al. 2016; Kirsch et al. 2015).

\section{Concentration-response curves (CRCs)}

After washouts, main experiments were performed (in each individual preparation only one experimental curve was determined). To test the vascular contractile function, the endothelium-intact aorta was exposed to a cumulative concentration of phenylephrine. To examine the vasorelaxant response of Ach or sodium nitroprusside (SNP), arteries were pre-constricted submaximally with phenylephrine $(3 \mu \mathrm{M}$; this concentration was approximately equal to its $\mathrm{pEC}_{75}$ ). Phenylephrine produced the contraction of $7.0 \pm 0.2 \mathrm{mN}(n=72)$.

When a stable level of tone was reached, concentration-response curves were generated by cumulative addition of Ach or SNP. 


\section{Potential mechanisms involved in vasodilatory effect of acetylcholine and sodium nitroprusside in LBMR and HBMR groups}

To examine the mechanisms involved in the vasodilatory effect of Ach, aorta rings were incubated for $30 \mathrm{~min}$ with the following substances: $N^{G}$-nitro-L-arginine methyl ester (L-NAME) $100 \mu \mathrm{M}$ (nitric oxide synthase inhibitor), indomethacin (INDO) $10 \mu \mathrm{M}$, (cyclooxygenase inhibitor); tetraethylammonium (TEA) $1 \mathrm{mM}$ (non-selective blocker of calcium-sensitive $\mathrm{K}^{+}$channels). To determine the mechanisms of the vasorelaxant effects of SNP, certain tissues were pretreated for $30 \mathrm{~min}$ with TEA. Control samples were treated with respective vehicle (Ach/SNP) only.

\section{Drugs}

(R)-Phenylephrine hydrochloride, acetylcholine chloride, sodium nitroprusside, L-NAME, tetraethylammonium chloride hydrate, indomethacin (Sigma, Munich, Germany) were dissolved in deionized water with the exception of indomethacin (which was dissolved in $0.5 \mathrm{M} \mathrm{NaHCO}_{3}$ ). $\mathrm{KCl}$ was obtained from Chempur, Piekary Śląskie, Poland.

\section{Immunohistochemistry for KCNN4, S100A6 and von Willebrand factor}

During the preparation of aortas, its segment was taken, immediately fixed in $10 \%$ formalin and processed routinely for embedding in paraffin. Sections were cut at $4 \mu \mathrm{m}$ thickness and stained in hematoxylin and eosin for general histological evaluation.

In the immunohistochemical study, the EnVision method was used according to Kasacka et al. (2015) using antibodies against KCNN4 (potassium channel, calcium-activated intermediate/small conductance subfamily $\mathrm{N}$ alpha, member 4) (1:1000-incubation $24 \mathrm{~h}$ in $+4^{\circ} \mathrm{C}$; rabbit Anti-KCNN4antibody (cat. no. Ab110105); Abcam, UK) and von Willebrand factor (vWB) (1:2000-incubation $2 \mathrm{~h}$ in RT, Polyclonal Rabbit Anti-Human (cat. no. A 0082); Dako Denmark A/S, Produktionsvej 42, DK-2600 Glostrup), S100A6-polyclonal rabbit antibody $\left(1: 500\right.$-incubation $24 \mathrm{~h}$ in $+4{ }^{\circ} \mathrm{C}$; purchased from Nencki Institute of Experimental Biology, produced in-house) in a humidified chamber.

Antigen retrieval was performed before commencing IHC staining: for KCNN4 is Target Retrieval Solution High pH (S2369; Dako Denmark A/S, Produktionsvej 42, DK-2600 Glostrup), for vWB is Target Retrieval Solution (S1699; Dako Denmark A/S, Produktionsvej 42, DK-2600 Glostrup) and for S100A6 and using Target Retrieval Solution with pH 9.0 (S 2367, Dako Denmark A/S, Produktionsvej 42, DK-2600 Glostrup). After being cooled to room temperature, sections were incubated with the Peroxidase Blocking
Reagent (S 2001 Dako Denmark A/S, Produktionsvej 42, DK-2600 Glostrup) for $10 \mathrm{~min}$, to block endogenous peroxidase activity. Subsequently sections were incubated with suitable primary antibodies. Procedure was followed by incubation with secondary antibody (conjugated to horseradish peroxidase-labeled polymer). The bound antibodies have visualized by 1-min incubation with liquid 3,3'-diaminobenzidine substrate chromogen. The sections were finally counterstained in hematoxylin QS $(\mathrm{H}-3404$, Vector Laboratories; Burlingame, CA), mounted and evaluated under light microscope. Appropriate washing with wash buffer (S 3006 Dako Denmark A/S, Produktionsvej 42, DK-2600 Glostrup) was performed between each step. The specificity of the antibodies included a negative control, in which the antibodies were replaced by normal rabbit serum (Vector Laboratories, CA) at the respective dilution (no staining), and positive control, prepared with mice heart for KCNN4 and S100A6 and mice lung for vWB. The obtained results of immunohistochemical staining were submitted for evaluation in an Olympus BX41 microscope with an Olympus DP12 camera under a magnification of $200 \times(20 \times$ lens and $10 \times$ eyepiece; each field was $0.785 \mathrm{~mm}^{2}$ ) and submitted to morphometric evaluation using software for image analysis (NIS-Elements Advanced Research software of Nikon). For each immunohistochemical staining were performed measurements of immunohistochemical reaction intensity per group of mice $(5$ mice $\times 3$ scraps $\times 10$ randomly selected microscopic fields). The intensity of the immunohistochemical reaction was measured using a 0-256 gray-scale level, in which completely black pixels were given a value of 256 and white or bright pixels a value of 0 (Baranowska-Kuczko et al. 2016).

\section{Statistical analysis}

For contractile responses to Phe, we analyzed the data as percentage of the reference response to the second $60 \mathrm{mM} \mathrm{KCl}$. All vasodilatory effects produced by Ach were expressed as the percentage of the relaxation after the isometric precontraction induced by Phe.

The GraphPad Prism 5.0 software (California, USA) was used to plot the mean data as sigmoidal CRCs curves:

$Y=$ Bottom $+($ Top - Bottom $) /\left(1+10^{\left(\operatorname{logEC}_{50}^{-X}\right)}\right)$

where $X$ is the logarithm of the molar concentration of the agonist and $Y$ is the percent response. The curves were used to determine potency $\left(\mathrm{pEC}_{50}=-\operatorname{logEC_{50}}\right.$ or $\mathrm{pEC}_{25}=-\log \mathrm{EC}_{25}$, where $\mathrm{EC}_{50}$ or $\mathrm{EC}_{25}$ is the concentration (M) of agonist that produced the 50 or $25 \%$-maximal effects) and maximal response $\left(R_{\max }\right)$ values as the effects of the highest concentration of the particular agonist (Kenakin 2019). 
All results are presented as the mean \pm standard error of the mean (SEM). BMR was analyzed by means of ANCOVA with the line type as a fixed factor and body mass as a covariate. For statistical calculation, in immunohistochemistry parametric ANOVA was used. Statistical comparisons of the CRCs of two or more treatment groups to the same control were performed using an analysis of variance (ANOVA) followed by Dunnett's multiple comparison test of the whole data set. Student's $t$ test for unpaired data was used where necessary. Differences were considered significant when $p<0.05$.

\section{Results}

\section{BMR values}

Mice originated from each specific line type differ significantly with respect to basal metabolic rate $(F=1442.58$; $p<0.0001)$, but not body mass $(F=1.91, p=0.273)$. Such a marked divergence in BMR between selection lines constitutes a justification for testing the associations between genetically based differentiation in energy expenditures and the function and structure of thoracic aorta as a potential risk factor for developing cardiovascular diseases (Table 1).

\section{Morphological features of aorta}

There were no histopathological changes observed in the aortic wall of the examined mice (Fig. 1a, b). Morphometric studies showed a significant between-line difference in the thickness of the wall thickness and diameter of aortas. The aorta of the HBMR animals had thicker walls and a larger diameter (Table 2).

The antisera staining against $\mathrm{S} 100$ calcium-binding protein A6 (S100A6) gave positive results in the aortas of all studied mice, with S100A6 protein found in endothelial cells and smooth muscle cells of the aortic wall (Fig. 1c, d). The density and intensity of S100A6-staining were weaker in the HBMR mice as compared with that recorded in the LBMR animals $(p<0.01)$ (Fig. 1i).

Immunohistochemical detection of KCNN4 channels in the aortas revealed their presence in myocytes and

Table 1 The BMR and body mass values

\begin{tabular}{llll}
\hline & $n$ & Body mass $(\mathrm{g})$ & BMR $\left(\mathrm{mLO}_{2} / \mathrm{h}\right)$ \\
\hline LBMR & 5 & $36.23 \pm 2.49$ & $41.43 \pm 2.75$ \\
HBMR & 5 & $34.28 \pm 1.92$ & $69.04 \pm 2.14^{\# \#}$ \\
\hline
\end{tabular}

The results are expressed as a as the mean \pm SEM. $n$ represents the number of animals

${ }^{\# \# \#} p<0.001$ compared to the LBMR group endothelial cells (Fig. 1e, f). The density of KCNN4 channels in the aortas of the HBMR mice characterized by high metabolic rate, measured as the intensity of immunohistochemical reaction, was significantly higher $(p<0.01)$ when compared to the LBMR animals (Fig. 1j).

The antisera against von Willebrand factor stained the corresponding endothelial cells, recognizing their site and morphology in the aortas. The analysis of vWF immunoreactivity showed endothelial cells forming the continuous layer of the aortic lumen, which attests to the integrity of aortic endothelium in all studied mice (Fig. 1g, h).

\section{Functional features of aorta}

\section{Vasoconstrictor responses to phenylephrine}

The vasoconstrictor under study, the $\alpha_{1}$-adrenoceptor agonist, phenylephrine (0.0001-30 $\mu \mathrm{M}$, Phe), induced a concentration-dependent contraction of mouse aorta rings isolated from LBMR and HBMR $\left(\mathrm{pEC}_{50}=6.5 \pm 0.1\right.$, $R_{\max }=78.3 \pm 5.7 \%, n=5$ and $6.6 \pm 0.1,83.3 \pm 3.6 \%, \mathrm{n}=5$, respectively; Fig. 2).

\section{Influence of endothelium denudation and L-NAME, indomethacin and TEA on the relaxation induced by acetylcholine in the isolated aorta rings}

Acetylcholine (Ach, $0.001-30 \mu \mathrm{M}$ ) produced concentrationdependent relaxation of isolated mouse aorta pre-constricted with Phe in the LBMR and HBMR animals (for the respective $\mathrm{pEC}_{25}$ and $R_{\text {max }}$, see: Fig. 3a, b). The relaxation response to Ach was almost completely blocked by endothelium denudation in isolated aorta rings in mice from both selected lines (Fig. 3a, b).

Blockage of NO synthase with L-NAME $(100 \mu \mathrm{M})$ resulted in the significant rightward displacement of the relaxation response curve to Ach and reduction of its efficacy in isolated aortas from the HBMR and LBMR mice (for $R_{\max }$ values, see Table 3, Fig. 3a, b). The reduction was significantly stronger in isolated aortas from HBMR than LBMR mice $(p<0.01)$.

Indomethacin $(10 \mu \mathrm{M}$, the COX-1/COX-2 inhibitor) reduced the relaxant effect elicited by the highest concentration of Ach $(30 \mu \mathrm{M})$ in isolated aortas from HBMR and LBMR (for $\mathrm{pEC}_{25}$ and $R_{\max }$ values, see Table 3, Fig. 3a, b). The reduction was stronger in isolated aortas from the HBMR than LBMR mice. Likewise, TEA (10 mM, nonselective calcium-sensitive $\mathrm{K}^{+}$channel inhibitor) reduced the relaxant effect of Ach $(30 \mu \mathrm{M}$. The vasorelaxation induced by Ach in the presence of TEA was more potent in isolated aortas from HBMR compared with LBMR mice ( $R_{\max }$ values, see Table 3, Fig. $3 \mathrm{a}$, b). 


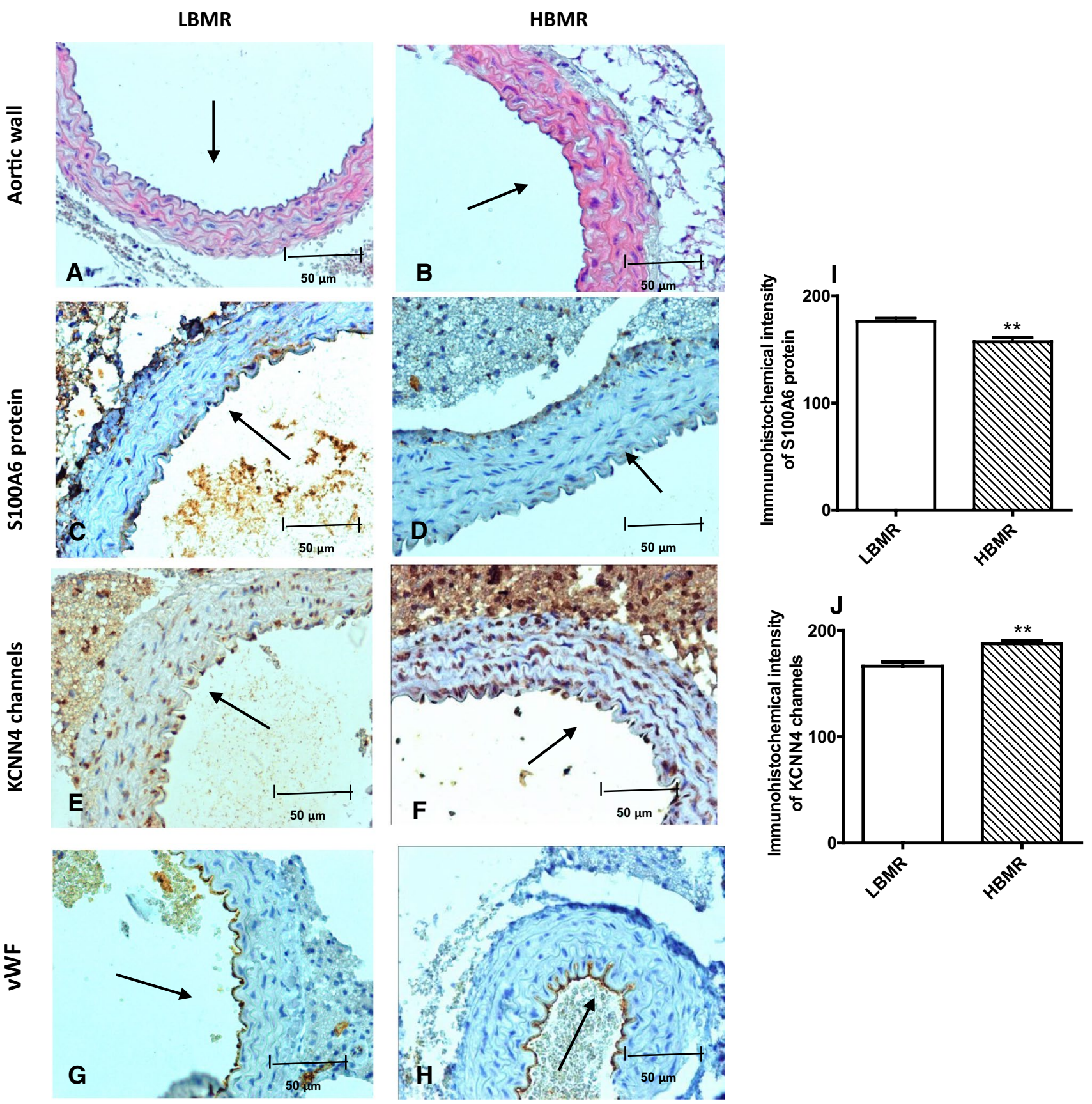

Fig. 1 Representative images of the aortic wall $(\mathbf{a}, \mathbf{b})$, immunodetection of S100A6 (c, d), immunohistochemical reaction for KCNN4 channels $(\mathbf{e}, \mathbf{f})$, immunolocalization of $\operatorname{vWF}(\mathbf{g}, \mathbf{h})$ in the vessels from LBMR and HBMR mice. Scale bars $-50 \mu \mathrm{m}$. The bar graph illustrates the intensity of the immunohistochemical reaction for the S100A6 (i) and KCNN4 (j) protein in the aortas. Mean \pm SEM of $n=5$ animals for each bar; * $p<0.01$ by a Student's $t$ test

\section{Influence of TEA on the relaxation induced by sodium nitroprusside in the isolated aorta rings}

SNP $(0.0001-3 \mu \mathrm{M})$ the NO donor, endothelium-independent vasodilator, produced concentration-dependent relaxation of the isolated mouse aorta pre-constricted with phenylephrine (Fig. 4a, b). SNP was more potent as a vasodilator in the isolated aortas of the HBMR than LBMR mice $\left(\mathrm{pEC}_{50}=7.8 \pm 0.1, n=5\right.$, and $\left.7.3 \pm 0.1, n=6 ; p<0.01\right)$ and its efficacy was comparable $\left(R_{\max }=104.1 \pm 7.1 \%\right.$ and $106.2 \pm 5.1 \%$ ).

Pre-treatment with the non-selective blocker of $\mathrm{KCa}$ channels TEA (1 mM) shifted the CRCs for SNP to the right by a factor of 8 and 3 in arteries from HBMR and LBMR mice, 
Table 2 The values of wall thickness, vessel diameter and wall thickness to diameter ratio

\begin{tabular}{lllll}
\hline & $n$ & Wall thickness $(\mu \mathrm{m})$ & Vessel diameter $(\mu \mathrm{m})$ & $\begin{array}{l}\text { The ratio of wall } \\
\text { thickness to } \\
\text { diameter }\end{array}$ \\
\hline LBMR & 5 & $43.9 \pm 0.65$ & $235.1 \pm 2.13$ & $0.19 \pm 0.006$ \\
HBMR & 5 & $61.7 \pm 1.85^{\#}$ & $246.2 \pm 1.76^{\#}$ & $0.25 \pm 0.017^{\#}$ \\
\hline
\end{tabular}

The results are expressed as mean \pm SEM. $n$ represents the number of animals ${ }^{\#} p<0.05$

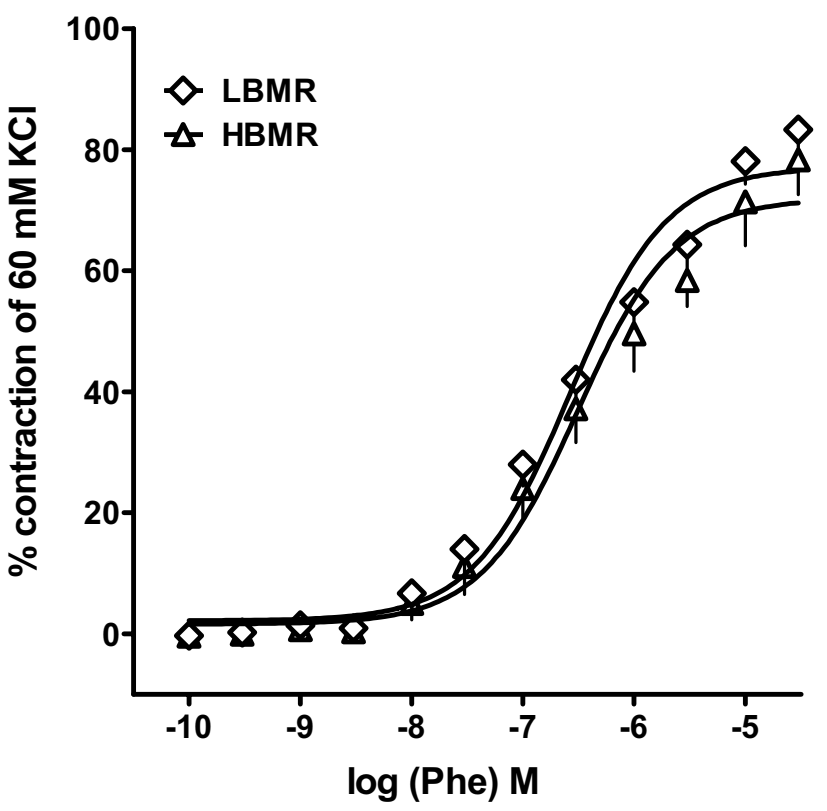

Fig. 2 Influence of phenylephrine (Phe) on the contractile effects in the isolated mouse aorta from HBMR and LBMR mice. For contractile responses to Phe, data are shown as a percentage of the reference response to the second $60 \mathrm{mM} \mathrm{KCl}$. Mean \pm SEM of $n=5$ animals for each curve. The results were analyszd by means of Student's $t$ test

respectively, and significantly attenuated potency in response to $\mathrm{SNP}\left(\mathrm{pEC}_{50}=6.9 \pm 0.1, n=5, p<0.05\right.$ and $6.9 \pm 0.1$, $n=6, p<0.001)$. TEA reduced the vasorelaxant efficacy of SNP in aortas from the HBMR $\left(R_{\max }=78.4 \pm 5.1 \%, n=5\right.$; $p<0.05)$ but not LBMR mice $\left(R_{\max }=93.9 .1 \pm 3.5 \%, n=6\right)$ (Fig. 4a, b).

\section{Discussion}

In this article, we used an animal model to study associations between genetically conditioned whole-body basal metabolic rate and physiological and structural properties of the thoracic aorta as risk factors of cardiovascular diseases development. High-BMR mice had significantly wider diameter and thicker middle layer of aorta compared to their counterparts selected for low BMR (Fig. 1a, b). Interestingly, the density of S100 calcium-binding protein A6 was significantly lower, while KCNN4 channels higher, in the HBMR animals (Fig. 1i, j, respectively). The differences in BMR were also reflected in the functional differentiation of thoracic aorta. We observed stronger inhibition of the endotheliumdependent relaxation of the aorta in the HBMR animals. Similarly, tetraethylammonium- and sodium nitroprussideinduced relaxation showed stronger vasodilatory effect of the muscle in examined aortas of mice from the high-BMR line. Our results, therefore, demonstrate that marked differences in structure and function of aortas correlate with genetically determined differentiation of BMR.

\section{Aortic function}

Among numerous factors contributing to CVD development, regulation of blood pressure and flow by nitric oxide (NO) and prostacyclins seems to play the main role (Deanfield et al. 2007; Katusic et al. 2012). They act via intracellular accumulation of the second way mediators, such as cyclin adenosine/guanosine monophosphate (cAMP and/or cGMP) (Ledoux et al. 2006). In consequence, an increased concentration of cAMP/cGMP, activates (open) $\mathrm{K}^{+}$channels in the cell membrane, which allows $\mathrm{K}^{+}$efflux of the cell, causing a decrease in membrane potential, hyperpolarization and closing calcium channels, affecting a vascular relaxation. Our results showed significant differences in inhibition of the endothelium-dependent relaxation of the aortas between the mouse lines. Both NO and prostacyclins were more active in the arteries of the HBMR animals and played a significant role in Ach-induced relaxation of vessels. Several clinical studies indicate that deficiency of nitric oxide weakens the diastolic ability of aorta and increases the risk of hypertension (Doroszko et al. 2008). Therefore, our results suggest that high organismal energy expenditure may contribute to increased aortic diastolic capacity. Such physiological correlation should protect against an increase in arterial blood pressure and development of cardiovascular disorders.

\section{Potassium channels}

Incubation of aortas in a medium containing tetraethylammonium revealed that the vessel relaxation is associated with 
A

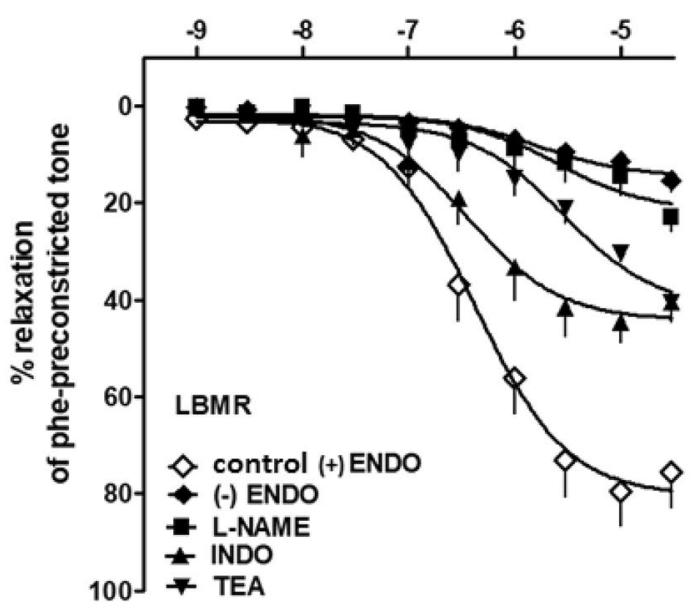

B

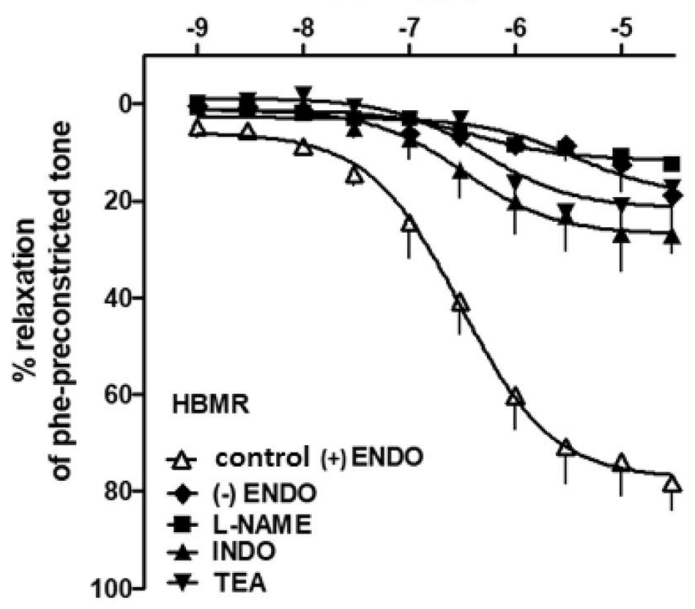

Fig. 3 Influence of endothelium denudation, L-NAME, indomethacin (INDO) and TEA on the relaxation induced by Ach in the isolated aorta rings from LBMR (a) and HBMR mice (b). Results of relaxation are expressed as a percentage relaxation of the isometric contraction induced by phenylephrine (Phe) $(3 \mu \mathrm{M})$. Mean \pm SEM of $n=4-5$ animals for each curve. Differences between concentration were analyzed by one-way analysis of variance (ANOVA) and between LBMR and HBMR groups were determined by Student's $t$ test. See Table 3 for values and statistical comparisons
Table 3 Effect of endothelium denuded, L-NAME, indomethacin (INDO), tetraethylammonium (TEA) on acetylcholine- induced relaxation responses in the phenylephrine-precontracted isolated aorta rings from mouse with low (LBMR) and high basal metabolism (HBMR)

\begin{tabular}{|c|c|c|c|c|c|c|}
\hline \multirow{2}{*}{$\begin{array}{l}\text { Relaxation responses to Ach } \\
\text { Group }\end{array}$} & \multirow[t]{2}{*}{$n$} & \multicolumn{2}{|l|}{ LBMR mice } & \multirow[t]{2}{*}{$n$} & \multicolumn{2}{|l|}{ HBMR mice } \\
\hline & & $\mathrm{pEC}_{25}$ & $R_{\max }(\%)$ & & $\mathrm{pEC}_{25}$ & $R_{\max }(\%)$ \\
\hline Control (+ENDO) & 5 & $6.7 \pm 0.1$ & $75.5 \pm 8.4$ & 5 & $6.9 \pm 0.1$ & $78.3 \pm 5.5$ \\
\hline$(-)$ ENDO & 4 & ND & $15.3 \pm 2.5 * * *$ & 4 & ND & $18.9 \pm 8.7 * * *$ \\
\hline L-NAME $(100 \mu \mathrm{M})$ & 5 & ND & $22.8 \pm 3.0 * * *$ & 5 & ND & $12.5 \pm 1.1 * * *$,\#\# \\
\hline INDO $(10 \mu \mathrm{M})$ & 4 & $6.3 \pm 0.1 *$ & $40.4 \pm 4.2 * * *$ & 5 & $5.3 \pm 0.1 * * *, \# \#$ & $27.1 \pm 3.7 * * *, \#$ \\
\hline TEA (1 mM) & 4 & $5.3 \pm 0.1 * * *$ & $40.5 \pm 0.9 * * *$ & 4 & ND & $17.2 \pm 5.4 * * *$,\#\# \\
\hline
\end{tabular}

The results are expressed as mean \pm SEM. $n$ represents the number of animals

${ }^{\#}, * p<0.05 ;{ }^{\# \#} p<0.01,{ }^{\# \# \#, * * * p} p<0.001$, compared to the respective control group (*to control LBMR or to control HBMR, as determined by one-way ANOVA followed by Dunnett's post hoc test; "between LBMR and HBMR group, by a Student's $t$ test for unpaired data). In case of below-range extent of vasorelaxant effect of Ach under assumed conditions, specific values were not determined (ND) the density of potassium channels located in the endothelial cells of the artery. In this case, stronger inhibition of Ach-induced relaxation was also noted in the aortas of the HBMR mice. Moreover, the study of the SNP-induced relaxation showed that stronger relaxation of the arterial muscle layer of the HBMR mice depended on the level of NO. The stronger inhibition of relaxant following the use of SNP and TEA in isolated aortas of the HBMR mice suggests the presence of a large number of potassium channels $\left(\mathrm{BK}_{\mathrm{Ca}} /\right.$ $\mathrm{K}_{\mathrm{Ca}}$ 1.1) located in the smooth muscles of blood vessels. The study on the $\mathrm{K}_{\mathrm{Ca}} 3 \cdot 1$-deficient mice $\left(\mathrm{K}_{\mathrm{Ca}} 3.1^{-/-}\right)$, testing the functional role of the endothelial intermediate conductance $\mathrm{K}_{\mathrm{Ca}}\left(\mathrm{IK}_{\mathrm{Ca}} / \mathrm{K}_{\mathrm{Ca}} 3.1\right)$, showed that in response to Ach the endothelial and smooth muscle hyperpolarization is reduced in $\mathrm{K}_{\mathrm{Ca}} 3.1^{-1-}$ individuals ( $\mathrm{Si}$ et al. 2006). Relaxation properties of aortas, therefore, suggest their functional link with the amount of potassium channels observed in arteries of the HBMR individuals. Higher density of $\mathrm{BK}_{\mathrm{Ca}} / \mathrm{K}_{\mathrm{Ca}} 1.1$ channels should be also directly coupled with the thickening of aorta observed in the HBMR mice. $\mathrm{BK}_{\mathrm{Ca}} / \mathrm{K}_{\mathrm{Ca}} 1.1$ are activated (opened) by changes in electrical potential of the membrane and/or by increases in the concentration of intracellular calcium ion (Yuan et al. 2010). The immunohistochemical staining corroborated the between-line differentiation of physiological properties of aorta observed in the functional test. The HBMR mice were characterized by significantly higher density of KCNN4 channels in the main artery compared with the LBMR counterparts. The KCNN4 protein is a part of the potentially heterotetrameric voltage-independent potassium channels (Steudel et al. 2017). It contributes to NO generation and endothelium-dependent hyperpolarization of vascular smooth muscle (Félétou 2009). Our results 
A

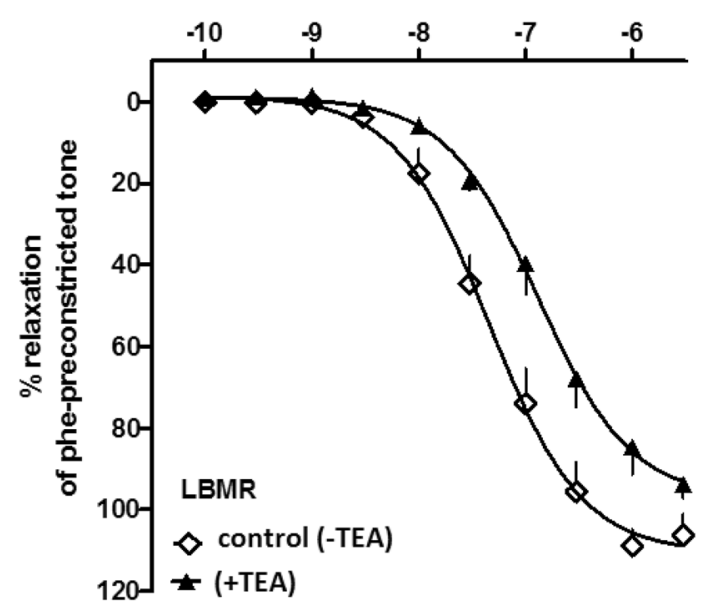

B

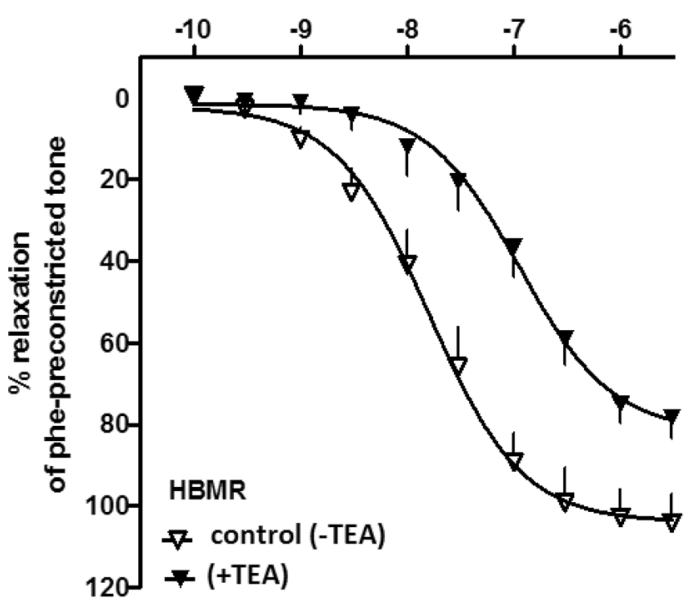

Fig. 4 Influence of TEA on the vasorelaxant effects of sodium nitroprusside (SNP) in the isolated mouse aorta from LBMR (a) and HBMR mice (b). Results of relaxation are expressed as a percent-

suggest the existence of the association between genetically determined variation of BMR and the activity of potassium channels.

Although increased activity of the potassium channels in the vascular smooth muscle cells may improve relaxation properties of aorta, the physiological consequences of chronic, high activity of $\mathrm{K}^{+}$channels remain poorly studied. Long-term alternation in both endothelium and ion channels may contribute to the development of cardiovascular disorders (Heaps et al. 2005; McNeish et al. 2005; Sobey 2001). Under pathological conditions, altered vascular $\mathrm{BK}_{\mathrm{Ca}} / \mathrm{K}_{\mathrm{Ca}} 1.1$ function may be either a cause (i.e., involved in the pathogenesis) or an effect (i.e., a secondary phenomenon or compensatory mechanism) of the disease (Sobey 2001). Changes in the activity of potassium channels are thought to be the result of a decreased number and/or reduced sensitivity of these channels to the physiological activators, like NO or prostacyclins (Sobey 2001). Studies on spontaneously hypertensive rats revealed that $\mathrm{K}_{\mathrm{Ca}}$ channels are highly activated in the resting state of carotid, femoral and mesenteric arteries (Asano et al. 1993). However, an increase in transmembrane flow of $\mathrm{K}^{+}$ions manifesting stronger contraction of the vessels reported by Asano et al. (1993) was not noted in our study. Similarly, an increase of the activity of the $\mathrm{BK}_{\mathrm{Ca}}$ l $\mathrm{K}_{\mathrm{Ca}} 1.1$ channels in blood vessels affected by atherosclerosis and/or hypertension is corroborated by studies on animals fed a high-fat diet (Sobey 2001). Although such increase is not associated with alternation in activity of NO-depended cGMP relaxant, observed changes manifest a serious dysfunction of endothelium-dependent aorta relaxation (Sobey 2001). This is in agreement with growing evidences suggesting that other (i.e., genetic) factors

age relaxation of the isometric contraction induced by phenylephrine (Phe) $(10 \mu \mathrm{M})$. Mean \pm SEM of $n=5$ animals for each curve. The results were analyzed by means of Student's $t$ test

may play a considerable role in the modification of the function of the $\mathrm{Ca}^{2+}$-activated $\mathrm{K}^{+}$channels, contributing to the differences in the functional properties of artery endothelium ( $\mathrm{Lu}$ et al. 2005; Martens and Gelband 1996).

\section{Calcium-binding proteins}

The density of S100A6 that belongs to a member of the S100 family of EF-hand $\mathrm{Ca}^{2+}$-binding proteins in the endothelial and muscle cells of the aorta was significantly lower in the HBMR mice compared with LBMR individuals. The observed small amount of calcium-binding molecules suggests higher activity of potassium ion channels in the aortas of the HBMR mice. The opening of KCNN4 channels and outflow of $\mathrm{K}^{+}$ions from the cells decreases the cell membrane potential (hyperpolarization), closes of calcium channels, reduces intracellular calcium levels and results in the whole vessel relaxation (Matchkov 2010). Therefore, mice characterized by low metabolic rate and reduced potassium channel activity should have higher concentration of calcium ions and, therefore, impaired contractile properties of aorta. Since several studies suggest a higher level of calcium ions in the hypertensive cell (Asano et al. 1993; Tune et al. 2017), individuals characterized by lower energy expenditure should be at greater risk of increased blood pressure, and so CVD development. Arterial hypertension is one of the most significant modifiable risk factors in the prevention of cardiovascular disease (Schroeder et al. 2019). Here we demonstrated that genetically determined high BMR is generally coupled with a greater relaxation of aorta mediated by higher density of $\mathrm{K}^{+}$channels, which may potentially constitute protective mechanisms against hypertension. 


\section{Aortic structure}

A long-term arterial thickening lowers the activity of $\mathrm{K}^{+}$ channels reduces arterial flexibility, and promotes structural stiffness (Lee and Oh 2010). The permanent state of such a disturbance contributes to development of cardiovascular diseases including atherosclerosis, or hypertension (Costantino et al. 2016). Here we showed that the HBMR mice have significantly thicker middle layer of aorta compared to the LBMR individuals. Endothelial and vascular smooth muscle cells play a key role in the contractile and relaxation response of aorta (Costantino et al. 2016). They also contribute to the regulation of arterial blood pressure by releasing vasoactive factors that modulate the contractile state of the underlying smooth muscle (Berk 2001; Ghebre et al. 2016; Yun et al. 2016). In case of our animal model, the overgrowth of the myointimal layer of aorta presumably results from well-documented increase in the size of heart and greater burden of cardiovascular system in the HBMR animals (Konarzewski and Książek 2013; Ksiazek et al. 2004). Those changes in the vascular structure reported for the high-BMR mice are reminiscent of those observed in aging humans. The architecture of main arteries in older individuals is characterized by myointimal thickening, collagen deposition, perivascular fibrosis, and vessel dilatation in comparison to the younger ones (Costantino et al. 2016; Scioli et al. 2014). The overgrowth of smooth muscle layer and alternation in endothelial-to-muscle ratio remain a hallmark of the aged vasculature, leading to excessive vessels stiffness (Costantino et al. 2016; Lee and Oh 2010). The changes in arterial stiffness may also result from altered vascular tone, representing the imbalance between vasoconstriction and vasorelaxation (Zieman et al. 2005). While decrease in aorta tension remains a major determinant of vascular impedance affecting pulsatile ejection of blood from the heart (Costantino et al. 2016; Agrawal et al. 2017) a longterm perturbation in artery contractility increases systolic pressure, promoting hypertension and vascular dysfunction.

Irrespective of age, high RMR/BMR constitutes an independent mortality risk in humans (Sadowska et al. 2017; Schrack et al. 2014). Therefore, the thickening of myointimal layer, observed in the HBMR mice, constitute an unique model to test for a risk of cellular drain, vascular disturbances, and CV-related morbidity in individuals with a higher rate of energy turnover.

\section{Conclusion}

In conclusion, the present study demonstrates the relevance of our animal model for studies on the associations between energy expenditures and structure as well as the function of aorta. Individuals characterized by high energy expenditures exhibit improved relaxation of aorta as a result of higher activity of $\mathrm{Ca}^{2+}$-activated $\mathrm{K}^{+}$channels in the endothelial and muscle layer of that artery. Several clinical studies indicate that aorta's flexibility remains the main factor determining diastolic capacity of vessels and, therefore, may protect against hypertension and CVD advancement. However, the high-BMR mice are also characterized by thicker myointimal layer and alternation in endothelial-to-muscle ratio. Since thickening and long-term over-activity of artery's middle layer promotes arterial stiffness and myocyte degradation, such structural changes of blood vessels may constitute the important risk factor of general CV failure. To resolve this inconsistency, future study on BMR-related changes in histological and physiological profiles of aortas in aging individuals would be of particular interest. Meanwhile, our research showed the functional link between organismal energy expenditures and structural/physiological properties of aorta, which demonstrated the usefulness of our model for the identification of potential risk factors of the development of CVD in humans.

Acknowledgements The authors would like to thank Prof. Barbara Malinowska from Department of Experimental Physiology and Pathophysiology, Medical University of Bialystok, for providing necessary space and equipment for the chosen analysis.

Author contributions $\mathrm{HC}$, MK, and HK: designed research; DS, SM, HK, MK, AS, ES, IK, MK, and HC: performed research and analyzed data; DS and SM: wrote the paper. All authors reviewed the manuscript.

Funding This work was supported by Medical University of Bialystok, Poland (N/ST/MN/18/001/3327).

\section{Compliance with ethical standards}

Conflict of interest The authors declare no conflict of interest.

Open Access This article is licensed under a Creative Commons Attribution 4.0 International License, which permits use, sharing, adaptation, distribution and reproduction in any medium or format, as long as you give appropriate credit to the original author(s) and the source, provide a link to the Creative Commons licence, and indicate if changes were made. The images or other third party material in this article are included in the article's Creative Commons licence, unless indicated otherwise in a credit line to the material. If material is not included in the article's Creative Commons licence and your intended use is not permitted by statutory regulation or exceeds the permitted use, you will need to obtain permission directly from the copyright holder. To view a copy of this licence, visit http://creativecommons.org/licenses/by/4.0/.

\section{References}

Agrawal H, Mery CM, Krishnamurthy R, Molossi S (2017) Anatomic types of anomalous aortic origin of a coronary artery: a 
pictorial summary. Congenit Heart Dis 12(5):603-606. https:// doi.org/10.1111/chd.12518

Asano M, Masuzawa-Ito K, Matsuda T, Imaizumi Y, Watanabe M, Ito K (1993) Functional role of Ca2+-activated K+ channels in resting state of carotid arteries from SHR. Am J Physiol 265:843-851. https://doi.org/10.1152/ajpheart.1993.265.3.H843

Baranowska-Kuczko M, Kozłowska H, Kloza M, Karpińska O, Toczek M, Harasim E, Kasacka I, Malinowska B (2016) Protective role of cannabinoid CB1 receptors and vascular effects of chronic administration of FAAH inhibitor URB597 in DOCA-salt hypertensive rats. Life Sci 151:288-299

Berk BC (2001) Vascular smooth muscle growth: autocrine growth mechanisms. Physiol Rev 81(3):999-1030. https://doi. org/10.1152/physrev.2001.81.3.999

Brzęk P, Bielawska K, Ksiażek A, Konarzewski M (2007) Anatomic and molecular correlates of divergent selection for basal metabolic rate in laboratory mice. Physiol Biochem Zool 80:491-499. https ://doi.org/10.1086/520617

Costantino S, Paneni F, Cosentino F (2016) Ageing, metabolism and cardiovascular disease. J Physiol 594:2061-2073. https://doi. org/10.1113/JP270538

Dang CV (2012) Links between metabolism and cancer. Genes Dev 26(9):877-890. https://doi.org/10.1101/gad.189365.112

Deanfield JE, Halcox JP, Rabelink TJ (2007) Endothelial function and dysfunction: testing and clinical relevance. Circulation 115:12851295. https://doi.org/10.1161/CIRCULATIONAHA.106.652859

Doroszko A, Andrzejak R, Szuba A (2008) Dysfunkcja śródbłonka i ADMA w patogenezie nadciśnienia tętniczego. Arterial Hypertension. 12(3):224-237

Fabbri E, An Y, Schrack JA, Gonzalez-Freire M, Zoli M, Simonsick EM, Guralnik JM, Boyd CM, Studenski SA, Ferrucci L (2015) Energy metabolism and the burden of multimorbidity in older adults: results from the baltimore longitudinal study of aging. J Gerontol A Biol Sci Med Sci 70(11):1297-1303. https://doi. org/10.1093/gerona/glu209

Félétou M (2009) Calcium-activated potassium channels and endothelial dysfunction: therapeutic options? Br J Pharmacol 156(4):545562. https://doi.org/10.1111/j.1476-5381.2009.00052.x

Ferrucci L, Corsi A, Lauretani F, Bandinelli S, Bartali B, Taub DD, Guralnik JM, Longo DL (2005) The origins of age-related proinflammatory state. Blood 105:2294-2299. https://doi.org/10.1182/ blood-2004-07-2599

Ghebre YT, Yakubov E, Wong WT, Krishnamurthy P, Sayed N, Sikora AG, Bonnen MD (2016) Vascular aging: implications for cardiovascular disease and therapy. Transl Med (Sunnyvale). https://doi. org/10.4172/2161-1025.1000183

Hamilton MT, Hamilton DG, Zderic TW (2007) Role of low energy expenditure and sitting in obesity, metabolic syndrome, type 2 diabetes, and cardiovascular disease. Diabetes 56:2655-2667. https://doi.org/10.2337/db07-0882

Heaps CL, Tharp DL, Bowles DK (2005) Hypercholesterolemia abolishes voltage-dependent $\mathrm{K}+$ channel contribution to adenosinemediated relaxation in porcine coronary arterioles. Am J Physiol Heart Circ Physiol 288:568-576. https://doi.org/10.1152/ajphe art.00157.2004

Heilbronn LK, de Jonge L, Frisard MI, DeLany JP, Larson-Meyer DE, Rood J, Nguyen T, Martin CK et al (2006) Effect of 6-month calorie restriction on biomarkers of longevity, metabolic adaptation, and oxidative stress in overweight individuals: a randomized controlled trial. JAMA 295:1539-1548. https://doi.org/10.1001/ jama.295.13.1539

Kasacka I, Piotrowska Z, Janiuk I (2015) Influence of renovascular hypertension on the distribution of vasoactive intestinal peptide in the stomach and heart of rats. Exp Biol Med 240(11):1402-1407. https://doi.org/10.1177/1535370215587533
Kathiresan S, Srivastava D (2012) Genetics of human cardiovascular disease. Cell 148(6):1242-1257. https://doi.org/10.1016/j. cell.2012.03.001

Katusic ZS, Santhanam AV, He T (2012) Vascular effects of prostacyclin: does activation of PPAR $\delta$ play a role? Trends Pharmacol Sci 33:559-564. https://doi.org/10.1016/j.tips.2012.05.005

Kenakin TP (2019) A pharmacology primer: techniques for more effective and strategic drug discovery, 5th edn. Academic, San Diego

Kirkby NS, Lundberg MH, Wright WR, Warner TD, Paul-Clark MJ, Mitchell JA (2014) COX 2 protects against atherosclerosis independently of local vascular prostacyclin: identification of COX-2 associated pathways implicate Rgl1 and lymphocyte networks. PLoS ONE 9(6):e98165. https://doi.org/10.1371/journ al.pone.0098165

Kirsch AH, Kirsch A, Artinger K, Schabhüttl C, Goessler W, Klymiuk I, Gülly C, Fritz GA, Frank S, Wimmer R et al (2015) Heterogeneous susceptibility for uraemic media calcification and concomitant inflammation within the arterial tree. Nephrol Dial Transplant 30(12):1995-2005. https://doi.org/10.1093/ndt/ gfv265

Konarzewski M, Książek A (2013) Determinants of intra-specific variation in basal metabolic rate. J Comp Physiol B 183(1):2741. https://doi.org/10.1007/s00360-012-0698-Z

Ksiazek A, Konarzewski M, Lapo IB (2004) Anatomic and energetic correlates of divergent selection for basal metabolic rate in laboratory mice. Physiol Biochem Zool 77(6):890-899. https://doi. org/10.1086/425190

Ledoux J, Werner ME, Brayden JE, Nelson MT (2006) Calcium-activated potassium channels and the regulation of vascular tone. Physiology (Bethesda) 21:69-78. https://doi.org/10.1152/physi ol.00040.2005

Lee HY, Oh BH (2010) Aging and arterial stiffness. Circ J 74:22572262. https://doi.org/10.5935/abc.20170091

Lu T, Wang XL, He T, Zhou W, Kaduce TL, Katusic ZS, Spector AA, Lee HC (2005) Impaired arachidonic acid-mediated activation of large-conductance $\mathrm{Ca} 2+$-activated $\mathrm{K}+$ channels in coronary arterial smooth muscle cells in zucker diabetic fatty rats. Diabetes 54:2155-2163. https://doi.org/10.2337/diabe tes.54.7.2155

Maciak S, Michalak P (2015) Cell size and cancer: a new solution to Peto's paradox? Evol Appl 8(1):2-8. https://doi.org/10.1111/ eva. 12228

Maciak S, Bonda-Ostaszewska E, Czarnołęski M, Konarzewski M (2014) Mice divergently selected for high and low basal metabolic rates evolved different cell size and organ mass. J Evol Biol 27(3):478-487. https://doi.org/10.1111/jeb.12306

Mancini C, Kenchaiah S, Bodurian E, Arai AE, Bandettini WP (2011) Embolization of an intracardiac thrombus during a cardiovascular magnetic resonance imaging study. Circultion 123(12):e388-389. https://doi.org/10.1161/CIRCULATIONAHA.110.983916

Martens JR, Gelband CH (1996) Alterations in rat interlobar artery membrane potential and $\mathrm{K}+$ channels in genetic and nongenetic hypertension. Circ Res 79:295-301

Matchkov VV (2010) Mechanisms of cellular synchronization in the vascular wall. Mechanisms of vasomotion. Dan Med Bull 57(10):B4191

McNeish AJ, Dora KA, Garland CJ (2005) Possible role for K+ in endothelium-derived hyperpolarizing factor-linked dilatation in rat middle cerebral artery. Stroke 36:1526-1532. https://doi. org/10.1161/01.STR.0000169929.66497.73

Mulvany MJ, Halpern W (1977) Contractile properties of small arterial resistance vessels in spontaneously hypertensive and normotensive rats. Circ Res 41:19-26

Nunney L (2018) Size matters: height, cell number and a person's risk of cancer. Proc Biol Sci 285(1889):pii:20181743. https://doi. org/10.1098/rspb.2018.1743 
Pelley JW (2012) Elsevier's integrated review biochemistry, 2nd edn. pp 171-179

Prentice HM (2008) Key contributions of the Na+/H+ exchanger subunit 1 and $\mathrm{HCO} 3$ - transporters in regulating neuronal cell fate in prolonged hypoxia. Am J Physiol Regul Integr Comp Physiol 294(2):448-450. https://doi.org/10.1152/ajpregu.00846.2007

Russell JC, Proctor SD (2006) Small animal models of cardiovascular disease: tools for the study of the roles of metabolic syndrome, dyslipidemia, and atherosclerosis. Cardiovasc Pathol 15(6):318 330. https://doi.org/10.1016/j.carpath.2006.09.001

Sadowska J, Gębczyński AK, Konarzewski M (2017) Metabolic risk factors in mice divergently selected for BMR fed high fat and high carb diets. PLoS ONE 12(2):e0172892. https://doi.org/10.1371/ journal.pone.0172892

Sawabe M (2010) Vascular aging: from molecular mechanism to clinical significance. Geriatr Gerontol Int 10(Suppl. 1):213-220. https ://doi.org/10.1111/j.1447-0594.2010.00603.x

Schmidt-Nielsen K (1997) Animal physiology: adaptation and environment. Cambridge University Press, Cambridge and New York (ISBN 978-0-521-57098-5)

Schrack JA, Knuth ND, Simonsick EM, Ferrucci L (2014) "IDEAL" aging is associated with lower resting metabolic rate: the baltimore longitudinal study of aging. J Am Geriatr Soc 62(4):667672. https://doi.org/10.1111/jgs.12740

Schroeder EC, Franke WD, Sharp RL, Lee DC (2019) Comparative effectiveness of aerobic, resistance, and combined training on cardiovascular disease risk factors: a randomized controlled trial. PLoS ONE 14(1):e0210292. https://doi.org/10.1371/journ al.pone.0210292

Scioli MG, Bielli A, Arcuri G, Ferlosio A, Orlandi A (2014) Ageing and microvasculature. Vasc Cell 6:19. https://doi. org/10.1186/2045-824X-6-19

Si H, Heyken WT, Wölfle SE, Tysiac M, Schubert R, Grgic I, Vilianovich L, Giebing G, Maier T, Gross V et al (2006) Impaired endothelium-derived hyperpolarizing factor-mediated dilations and increased blood pressure in mice deficient of the intermediateconductance Ca2+-activated K+ channel. Circ Res 99(5):537544. https://doi.org/10.1161/01.RES.0000238377.08219.0c

Skoczynska A, Martynowicz H (2005) The impact of subchronic cadmium poisoning on the vascular effect of nitric oxide in rats. Hum
Exp Toxicol 24(7):353-361. https://doi.org/10.1191/0960327105 ht536oa

Sobey CG (2001) Potassium channel function in vascular disease. Arterioscler Thromb Vasc Biol 21:28-38. https://doi.org/10.1161/01. ATV.21.1.28

Steudel FA, Mohr CJ, Stegen B, Nguyen HY, Barnert A, Steinle M, Beer-Hammer S, Koch P, Lo WY, Schroth W et al (2017) SK4 channels modulate $\mathrm{Ca}^{2+}$ signalling and cell cycle progression in murine breast cancer. Mol Oncol 11(9):1172-1188. https://doi. org/10.1002/1878-0261.12087

Tune JD, Goodwill AG, Sassoon DJ, Mather KJ (2017) Cardiovascular consequences of metabolic syndrome. Transl Res 183:57-70. https://doi.org/10.1016/j.trsl.2017.01.001

Wells S, Rafter N, Eggleton K, Turner C, Huang Y, Bullen C (2016) Using run charts for cardiovascular disease risk assessments in general practice. J Prim Health Care 8(2):172-178. https://doi. org/10.1071/HC15030

Yuan P, Leonetti MD, Pico AR, Hsiung Y, MacKinnon R (2010) Structure of the human BK channel Ca2+-activation apparatus at $3.0 \mathrm{~A}$ resolution. Science 329(5988):182-186. https://doi.org/10.1126/ science. 1190414

Yun S, Budatha M, Dahlman JE, Coon BG, Cameron RT, Langer R, Anderson DG, Baillie G, Schwartz MA (2016) Interaction between integrin $\alpha 5$ and PDE4D regulates endothelial inflammatory signalling. Nat Cell Biol 18(10):1043-1053. https://doi. org/10.1038/ncb3405

Zadelaar S, Kleemann R, Verschuren L, der Weij JV-V, Hoorn J, Princen HM, Kooistra T (2007) Mouse models for atherosclerosis and pharmaceutical modifiers. Arterioscler Thromb Vasc Biol 27:1706-1721. https://doi.org/10.1161/ATVBAHA.107.142570

Zieman SJ, Melenovsky V, Kass DA (2005) Mechanisms, pathophysiology, and therapy of arterial stiffness. Arterioscler Thromb Vasc Biol 25(5):932-943. https://doi.org/10.1161/01.ATV.0000160548 .78317 .29

Publisher's Note Springer Nature remains neutral with regard to jurisdictional claims in published maps and institutional affiliations. 